\title{
EVALUASI TINGKAT PARTISIPASI MASYARAKAT DALAM PENGELOLAAN IRIGASI DAERAH RAWA ANJIR SERAPAT KABUPATEN KAPUAS
}

\author{
Pining Sitohang 1 \\ ${ }^{1}$ Dinas Pekerjaan Umum dan Penataan Ruang Provinsi Kalimantan Tengah
}

\begin{abstract}
ABSTRAK
Salah satu desa yang berpotensi untuk pengembangan pertanian di Provinsi Kalimantan Tengah adalah desa Anjir Serapat I. Lokasi Daerah Rawa Anjir Serapat terletak disebelah kiri-kanan Anjir yang menghubungkan dua sungai yaitu Sungai Kapuas murung di Provinsi Kalimantan Tengah dengan Sungai Barito yang ada di Provinsi Kalimantan Selatan dengan Panjang $28 \mathrm{Km}$. Daerah rawa Anjir Serapat I berjarak lurus sekitar $160 \mathrm{~km}$ ke arah batas Provinsi Kalimantan Selatan melalui jalan trans Kalimantan. Dengan luas fungsional DIR Anjir Serapat Kabupaten Kapuas sebesar 3.248 Ha, dan memiliki potensi yang besar untuk meningkatkan produksi pertanian. Potensi itu dirasa masih belum optimal. Hal ini dapat dilihat dari hasil produksi padi yang masih belum maksimal. Untuk menanggulangi masalah tersebut diperlukan pendekatan kepada masyarakat tentang pentingnya pengelolaan tata air mikro yang merupakan tanggung jawab petani dan memberikan pemahaman tentang tata cara perawatan insfrastruktur yang sudah ada di lahan pertanian. Menurut Permen PUPR.29/PRT/M/2015 dalam pengembangan dan pengelolaan sistem irigsi rawa salah satunya adalah partisipasi masyarakat petani. Tujuan dari penelitian ini adalah menganalis tingkat partisipasi dan mengidentifikasi faktor-faktor yang mempengaruhi partisipasi masyarakat dalam pengelolaan irigasi rawa di daerah Anjir Serapat I Kabupaten Kapuas. Metode penelitian ini adalah metode survei yang menggambarkan pengaruh antara variabel-variabel yang tergabung dalam variabel jaringan irigasi yang ada dengan partisifatif petani dalam pemeliharaan jaringan irigasi tersier. Berdasarkan data yang terkumpul setiap variabel, dan setelah dilakukan analisis dengan perhitungan, tidak ditemukan hubungan dan berpengaruh nyata secara bersama-sama antara Aspek Teknis $\left(X_{1}\right)$, Aspek Sosial Budaya $\left(X_{2}\right)$ dan Aspek Sosial Ekonomi $\left(X_{3}\right)$ terhadap partisipatif petani $(Y)$. Dengan ratarata nilai kuantitatif sebesar $(22,37<25)$, petani masih tergolong belum partisipatif terhadap pemeliharaan jaringan irigasi yang ada.
\end{abstract}

Kata kunci: partisipasi masyarakat, irigasi, daerah rawa Anjir Serapat I.

\section{PENDAHULUAN}

Irigasi menjadi pendukung keberhasilan pembangunan pertanian dan merupakan kebijakan Pemerintah yang sangat strategis dalam pertumbuhan perekonomian nasional guna mempertahankan produksi swasembada beras. Menurut Peraturan Pemerintah nomor 20 tahun 2006 tentang irigasi pada ketentuan umum bab I pasal 1 berbunyi irigasi adalah usaha penyediaan, pengaturan dan pembuangan air irigasi untuk menunjang pertanian yang jenisnya adalah

Correspondence: Pining Sitohang

Email: sitohangpining@yahoo.co.id irigasi permukaan, rawa, air bawah tanah, pompa, dan tambak. Untuk mengalirkan air sampai pada areal persawahan diperlukan jaringan irigasi, dan air irigasi diperlukan untuk mengairi persawahan, oleh sebab itu kegiatan pertanian tidak dapat terlepas dari air.

Pengelolaan sistem irigasi bertujuan untuk mewujudkan pemanfaatan air dalam bidang pertanian yang diselenggarakan secara partisipasi, terpadu, berwawasan lingkungan, transparan, akuntabel, dan berkeadilan. Pengelolaan sistem irigasi secara transparan dan akuntabel mengandung pengertian bahwa pengelolaan sistem irigasi dilakukan secara terbuka dan dapat dipertanggungjawabkan. Irigasi mempunyai fungsi untuk mendukung produktivitas lahan pertanian, ketahanan 
pangan nasional, dan kesejahteraan masyarakat khususnya petani yang diwujudkan dengan mempertahankan keberlangsungan sistem irigasi melalui kegiatan pengelolaan sistem irigasi yang efisien dan efektif.

Berdasarkan ketentuan pasal 84 Undang-undang No. 7 Tahun 2004 tentang sumber daya air, menyatakan bahwa masyarakat yang dalam hal ini petani pemakai air mempunyai kesempatan yang sama untuk berperan serta dalam proses perencanaan, pelaksanaan, pengawasan terhadap pengelolaan sumber daya air khususnya pengelolaan irigasi. Dalam hal pembiayaan pelaksanaan operasi, pemeliharaan, dan rehabilitasi sistem irigasi primer dan sekunder dapat melibatkan peran serta masyarakat petani sesuai pasal 78 Ayat (3) Undangundang No. 7 Tahun 2004 tentang sumber daya air. Kebijakan pengelolaan sistem irigasi yang efektif dan efisien diperlukan untuk menjamin keberlangsungan sistem irigasi dan hak-hak atas air bagi semua pemakai air irigasi.

Salah satu desa yang berpotensi untuk pengembangan pertanian di Provinsi Kalimantan Tengah adalah desa Anjir Serapat I. Lokasi Daerah Rawa Anjir Serapat terletak disebelah kiri-kanan Anjir yang menghubungkan dua sungai yaitu Sungai Kapuas murung di Provinsi Kalimantan Tengah dengan Sungai Barito yang ada di Provinsi Kalimantan Selatan dengan Panjang 28 Km. Daerah Rawa Anjir Serapat memiliki potensi lahan rawa yang sangat luas.

Potensi itu dirasa masih belum optimal. Hal ini dapat dilihat dari hasil produksi padi yang masih belum maksimal. Untuk menanggulangi masalah tersebut diperlukan pendekatan kepada masyarakat tentang pentingnya pengelolaan tata air mikro yang merupakan tanggung jawab petani dan memberikan pemahaman tentang tata cara perawatan insfrastruktur yang sudah ada di lahan pertanian.

Konsep pendekatan partisipatif yang digunakan yaitu memberi kesempatan kepada petani melalui kelembagaan yang ada untuk terlibat dalam proses pemeliharaan jaringan irigasi tersier, mulai dari perencanaan, pelaksanaan, sampai kepada $\mathrm{O}$ dan $\mathrm{P}$ jaringan organisasi. Pendekatan dimulai dari petani yang akan menerima manfaat langsung dengan adanya pembangunan jaringan tersier tersebut.

Partisipasi petani dalam pemeliharaan jaringan irigasi tersier sebagai berikut:

a. Kegiatan gotong-royong melaksanakan pemeliharaan jaringan irigasi agar tujuan dari petani dapat tercapai dengan adanya kebersamaan antara pemerintah dan masyarakat petani.

b. Suatu kegiatan petani dalam bentuk bantuan pelaksanaan pemeliharaan sehingga beban pemerintah dapat berkurang serta program pemerintah tercapai.

c. Kepedulian masyarakat petani dalam pemeliharaan jaringan irigasi akibat terlaksananya pemberdayaan masayarakat.

d. Memberikan bantuan baik dalam bentuk pikiran, dana, dan tenaga dalam kegiatan pemeliharaan

Untuk mengetahui seberapa besar kepedulian/pastisipasi masyarakat, diperlukan penelitian lebih lanjut tentang kepedulian masyarakat dalam mengelola tata air mikro. Berdasarkan latar belakang inilah penulis ingin mengadakan penelitian lebih lanjut tentang Pengelolaan TAM di DIR Anjir Serapat I Desa Mambulau Tengah Kabupaten Kapuas dengan Pendekatan Partisipatif.

Berdasarkan uraian yang telah dipaparkan, maka rumusan masalah pada penelitian ini adalah "Bagaimana partisipasi/kepedulian masyarakat dalam mengelola irigasi daerah rawa di kawasan Anjir Serapat I Desa Mambulau Tengah Kabupaten Kapuas?" dan "Faktor-faktor apa saja yang mempengaruhi partisipasi masyarakat dalam pengelolaan irigasi rawa di daerah Anjir Serapat I Desa Mambulau Tengah Kabupaten Kapuas?

\section{METODE PENELITIAN}

Metode penelitian ini adalah metode survei yang menggambarkan pengaruh antara variabel-variabel yang tergabung dalam variabel jaringan irigasi yang ada dengan partisifatif petani dalam pemeliharaan jaringan irigasi tersier. Hal-hal yang berkaitan dengan 
metode survei yaitu:

a. Penelitian mencari dan menguji antar variabel.

b. Variabel-variabel yang diteliti tidak dimanipulasi

c. Variabel-variabel yang diteliti menyangkut peristiwa yang telah terjadi.

d. Penelitian menguji pengaruh partisifatif petani terhadap pemeliharaan jaringan irigasi tersier

e. Penelitian ini tidak terdapat kelompok pengontrol maupun eksperimental.

\subsection{Kuesioner}

Kuesioner untuk setiap variable terdiri dari 10 butir pertanyaan, dan untuk mendapatkan skor dari setiap jawaban responden, setiap pertanyaan mempunyai 4 alternatif jawaban berurutan dan berjenjang dari jawaban terbaik hingga terburuk. Adapun setiap pilihan jawaban diberi skor tertentu yaitu:

a. Jawaban a diberi skor 1;

b. Jawaban b diberi skor 2;

c. Jawaban c diberi skor 3;

d. Jawaban d diberi skor 4.

Sehingga skor yang nantinya diperoleh berada pada rentang 10 sarnpai dengan 40. Reliabilitas kuesioner dilakukan dengan menghitung indeks Alpha Cronbach. Kriteria reliabilitas kuesioner adalah jika indeks Alpha Cronbach $\geq 0,50$.

\subsection{Studi Literatur}

Studi literatur merupakan teknik pengumpulan data yang digunakan untuk mendapatkan informasi tentang teori dan konsep yang erat hubungannya dengan permasalahan yang diteliti. Teori dan konsep dalam penelitian ini terkait mengenai pengertian irigasi, pengelolaan irigasi, dan faktor-faktor yang tingkat partisipasi masyarakat.

\subsection{Dokumentasi}

Dokumentasi digunakan untuk mendapatkan informasi atau data yang berkaitan dengan penelitian. Dalam penelitian ini dokumentasi digunakan umtuk mendapatkan data lokasi daerah rawa.

\subsection{Pengumpulan Data}

Data yang dikumpulkan berupa data primer yaitu data yang diperoleh langsung dari wawancara maupun dari hasil pengisian kuesioner tentang masalah peran serta petani dalam partisifatif jaringan irigasi yang disebarkan kepada responden kepada petani di Kecamatan Kapuas Timur.

Selain itu, dikumpulkan pula data sekunder. Data sekunder dalam kajian ini diperoleh dari bahan-bahan atau dokumen-dokumen yang dikumpulkan dan diolah oleh pihak lain dalam bentuk publikasi. Data sekunder diperoleh dari Perkumpulan Petani Pemakai Air (P3A) di Kecamatan.

\section{HASIL DAN PEMBAHASAN}

\subsection{Aspek Teknis $\left(X_{1}\right)$ dengan (Y)}

Dari hasil penelitian yang dilakukan, aspek teknis memiliki rata-rata nilai kuantitatif sebesar $(27,31<50)$, hal ini menunjukkan bahwa aspek teknis masih tergolong menuju partisipatif karena kurangnya kesadaran, koordinasi, serta pengarahan dukungan oleh instansi terkait. Hasil perhitungan dapat dilihat pada Tabel 1 dan Gambar 1.

Tabel 1. Descriptive Statistics $X_{1}-Y$

\begin{tabular}{cccc}
\hline & Mean & $\begin{array}{c}\text { Std. } \\
\text { Deviation }\end{array}$ & $\mathrm{N}$ \\
\hline Aspek Teknis $\left(X_{1}\right)$ & 27,1 & 4,602 & 49 \\
Partisipasi Petani $(\mathrm{Y})$ & 22,59 & 6,058 & 49 \\
\hline
\end{tabular}




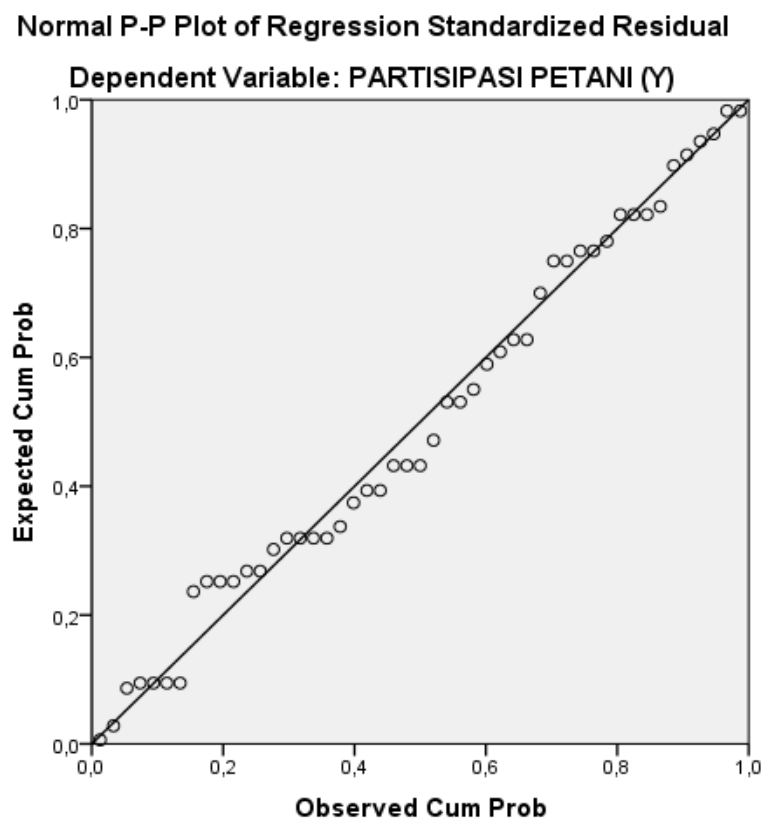

Gambar 1. Grafik Regresi Linier $X_{1^{-}} \mathrm{Y}$

\subsection{Aspek Sosial Budaya $\left(X_{2}\right)$ dengan (Y)}

Adapun untuk aspek sosial budaya memiliki rata-rata nilai kuantitatif sebesar $(27,51<50)$, hal ini menunjukkan bahwa aspek sosial budaya masih tergolong menuju partisipatif karena kurangnya pendidikan, pelatihan dan pembinaan serta dukungan oleh instansi terkait. Hasil perhitungan dapat dilihat pada Tabel 2 dan Gambar 2.

Tabel 2. Descriptive Statistics $\mathrm{X}_{2}-\mathrm{Y}$

Std.

Mean Deviation $\mathrm{N}$

\begin{tabular}{cccc}
\hline Aspek Sosial Budaya $\left(X_{2}\right)$ & 27,51 & 5,042 & 49 \\
& 22,59 & 6,058 & 49 \\
Partisipasi Petani (Y) & & \\
\hline
\end{tabular}

\subsection{Aspek Sosial Ekonomi $\left(X_{3}\right)$ dengan (Y)}

Sedangkan untuk aspek sosial ekonomi memiliki rata-rata nilai kuantitatif sebesar $(22,57<50)$. Hal ini menunjukkan bahwa sosial ekonomi masih tergolong belum partisipatif karena kurangnya perhatian dari instansi terkait dalam perkembangan sektor pertanian guna meningkatkan kesejahteraan petani.. Hasil perhitungan dapat dilihat pada Tabel 3 dan Gambar 3.
Tabel 3. Descriptive Statistics $X_{3}-Y$

\begin{tabular}{cccc}
\hline & & $\begin{array}{c}\text { Std. } \\
\text { Deviation }\end{array}$ & $\mathrm{N}$ \\
\hline & Mean & & \\
Aspek Sosial Ekonomi $\left(\boldsymbol{X}_{3}\right)$ & 22,57 & 3,731 & 49 \\
Partisipasi Petani (Y) & 22,59 & 6,058 & 49 \\
\hline
\end{tabular}

\subsection{Aspek Teknis $\left(X_{1}\right)$, Aspek Sosial Budaya $\left(X_{2}\right)$ dan Aspek Sosial Ekonomi $\left(X_{3}\right)$ dengan Partisipatif $(Y)$}

Adapun untuk analisa terhadap ketiga aspek, memiliki rata-rata nilai kuantitatif sebesar $(22,59<25)$, hal ini menunjukkan bahwa terjadi pengaruh secara bersama-sama antara aspek sosial budaya dan aspek sosial ekonomi, sedangkan aspek sosial ekonomi tergolong belum partisipatif terhadap partisipasi petani dalam pemeliharaan jaringan irigasi yang ada. Hasil perhitungan dapat dilihat pada Tabel 4 dan Gambar 4. 
Tabel 4. Descriptive Statistics $X_{1}, X_{2}$ dan $X_{3}-\mathrm{Y}$

\begin{tabular}{lccc}
\hline & Mean & Std. Deviation & $\mathrm{N}$ \\
\hline Aspek Teknis $\left(X_{1}\right)$ & 27,31 & 4,602 & 49 \\
Aspek Sosial Budaya $\left(X_{2}\right)$ & 27,51 & 5,042 & 49 \\
Aspek Sosial Ekonomi $\left(X_{3}\right)$ & 22,57 & 3,731 & 49 \\
Partisipasi Petani $(Y)$ & 22,37 & 2,073 & 49 \\
\hline
\end{tabular}

Normal P-P Plot of Regression Standardized Residual

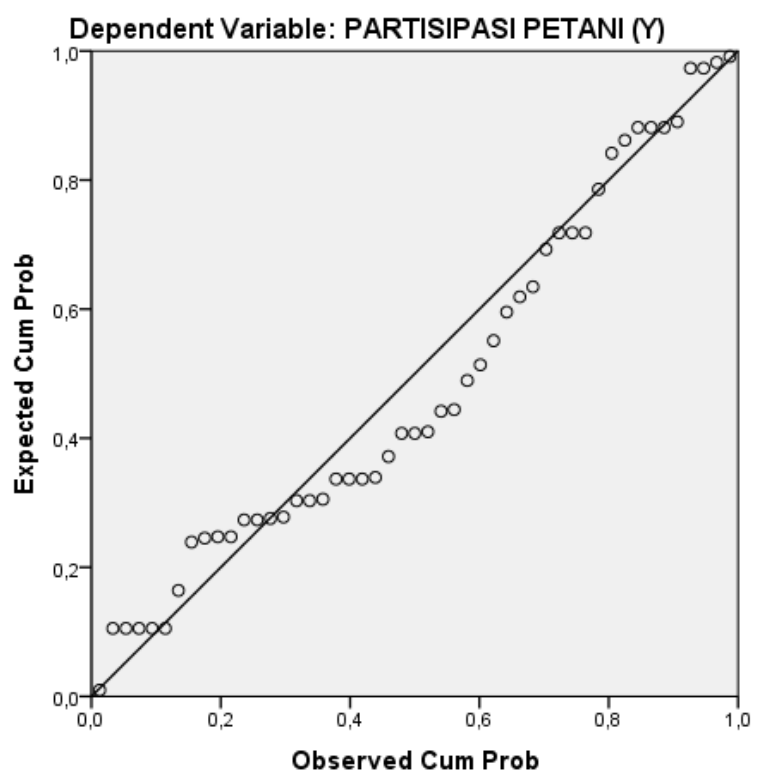

Gambar 2. Grafik Regresi Linier $X_{2}-\mathrm{Y}$

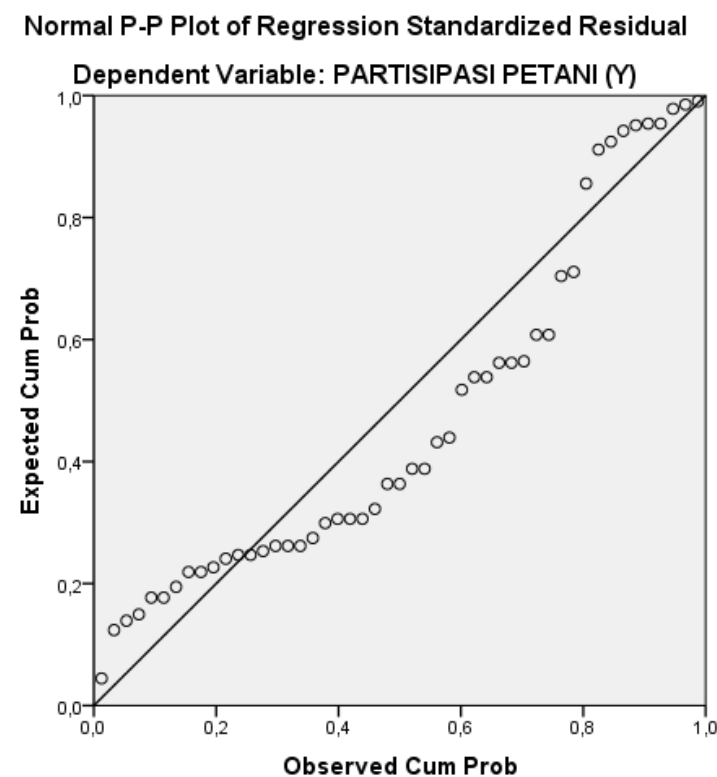

Gambar 3. Grafik Regresi Linier $X_{3}-\mathrm{Y}$ 


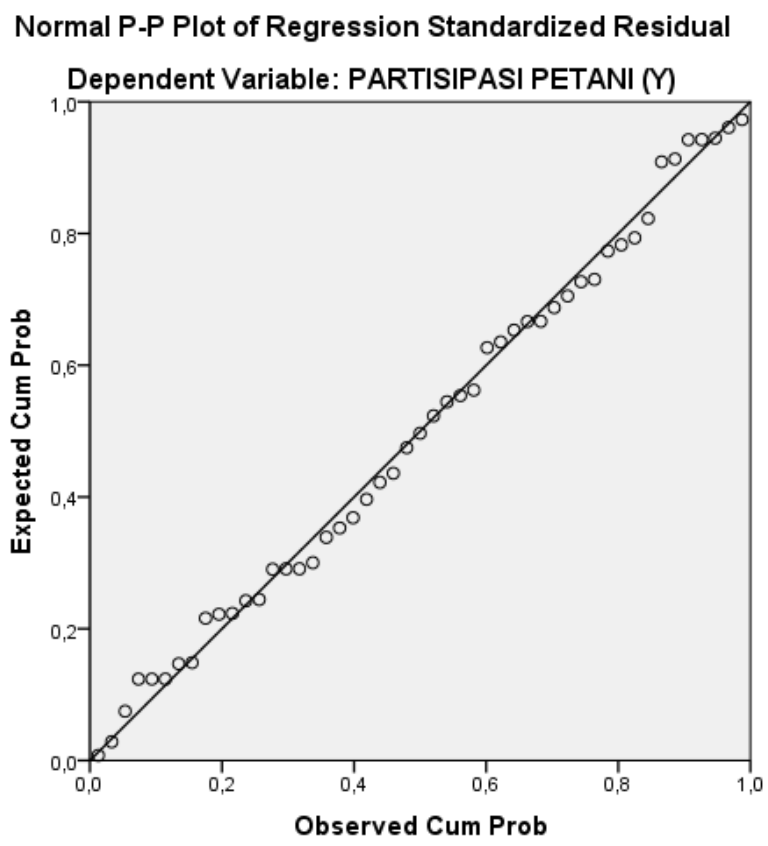

Gambar 4. Grafik Regresi Linier $X_{1}, X_{2}$ dan $X_{3}-Y$

Berdasarkan hasil kuesioner dapat ditabulasikan (rekapitulasi) menggunakan skala pengukuran Rating scale sebagai berikut Jumlah skor kriterium adalah Skor tertinggi tiap item dikali Jumlah pertanyaan dikali jumlah responden, sehingga:

Jumlah skor kriterium $=5 \times 40$ x $35=7000$

Maka, jumlah skor hasil pengumpulan data adalah 3560. Dengan demikian evaluasi tingkat partisipasi masyarakt dalam pengelolaan irigasi daerah rawa di anjir serapat Kabupaten Kapuas, menurut 35 responden yaitu $5560: 7000 \times 100 \%=$ $79,42 \%$ dari kritarium yang ditetapkan. Apabila diinterpretasikan nilai $79,42 \%$ terletak pada daerah baik. Sedangkan nilai 5560, termasuk dalam kategori interval baik. Secara kontinum dapat dilihat seperti Gambar 5.

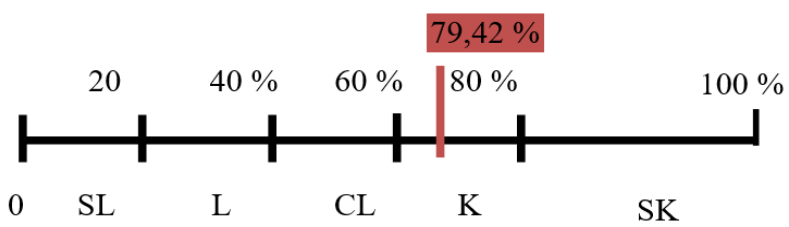

Gambar 5. Range skala persen

Dimana: SL= Sangat Lemah; $\mathrm{L}=\mathrm{Lemah}$; $\mathrm{CL}=$ Cukup Lemah; $\mathrm{K}=$ Kuat dan $\mathrm{SK}=$ Sangat Kuat.
Dengan demikian "evaluasi tingkat partisipasi masyarakt dalam pengelolaan irigasi daerah rawa di anjir serapat kabupaten Kapuas" menurut persepsi 35 orang termasuk dalam kategori interval (jarak antara dua nilai) lebih dekat ke baik (B) atau kuat.

\section{KESIMPULAN}

Berdasarkan hasil analisis terhadap hasil penelitian yang dilakukan dapat disimpulkan beberapa hal sebagai berikut.

1. Faktor-faktor yang mempengaruhi partisipatif petani dalam pengelolaan jaringan irigasi terdiri dari :

a. Kurangnya pelatihan, pendampingan, penyuluhan dan pembinaan P3A

b. Kurang aktifnya kepengurusan P3A

c. Belum adanya kesadaran petani untuk menimbulkan rasa memiliki jaringan irigasi yang ada

d. Faktor usia dan pendidikan juga sangat mempengaruhi partisipasi petani

2. Pengaruh yang terjadi diantara faktor-faktor tersebut adalah :

a. Pengaruh yang terjadi antara faktor sosial budaya dengan partisipatif (Y) termasuk kategori menuju partisipatif. Hal ini menunjukkan bahwa kegiatan pembinaan, pelatihan, penyuluhan dan 
pendampingan masih belum dilaksanakan secara rutin, sehingga petani masih belum memahami tanggung jawab terhadap pemeliharaan jaringan irigasi.

b. Pengaruh yang terjadi antara faktor sosial ekonomi dengan partisipatif termasuk kategori menuju partisipatif. Karena kegiatan pertanian, pembinaan, pemeliharaan, masih dilakukan seadanya tanpa ada perhatian dari pihak/instansi terkait. Sehingga mempengaruhi sosial ekonomi masyarakat petani.

\section{DAFTAR RUJUKAN}

Pemerintah Republik Indonesia. 2004. Undang-Undang Republik Indonesia tahun 2004 tentang Sumber Daya Air. Jakarta.

Bahua, M.I. 2007. Metode Perencanaan Partisipatif dalam Pembangunan Masyarakat.

Direktorat Jenderal Sumber Daya Air. 2006 Perkumpulan Petani Pemakai Air, Departemen Pekerjaan Umum Badan Penelitian dan Pengembangan Direktorat Jenderal Sumber Daya Air Bekerjasama dengan Japan International Cooperation Agency.

Furchon, A. 1982. Pengantar Penelitian dalam pendidikan, Usaha Nasional. Surabaya.

Hasan, M. 2002. Analisis data Penelitian dengan Statistik. PT. Bumi Aksara, Jakarta.

Hermawan. 2003. Pemberdayaan Petani pemakai Air (P3A) di kabupaten Lampung Tengah. Tesis Program Studi Magister Administrasi Publik Konsentrasi Kebijakan dan Otonomi Daerah. Universitas Gadjah Mada. Yogyakarta.

Hidayat, A. dan A. Mulyani. 2002. Lahan kering untuk pertanian. Dalam A. Abdurachman, Mappaona, dan Saleh (Ed.). Pengelolaan Lahan Kering Menuju Pertanian Produktif dan
Ramah Lingkungan. Pusat Penelitian dan Pengembangan Tanah dan Agroklimat, Bogor

Moleong, L.J Metodologi Penelitian Kualitatif. Bandung

Mustaniroh, S.A. 2001, Jurnal Teknologi Pertanian, Vol. 2 No. 2 Agustus

Nazir, Moh., ph.D. 2003. Metode penelitian, Ghalia Indonesia. Jakarta.

Prihanita, P. 2006. Hubungan Partisifatif Petani terhadap Kapasitas Irigasi. Studi Kasus di Blok Pulutan Jaringan Irigasi Sedadi Kecamatan Godong Kabupaten Grobongan. Universitas Negeri Semarang.

Rachman, B. dan K. Kariyasa 2001. Dinamika Kelembagaan Pengelolaan Air Irigasi, Pusat Penelitian dan Pengembangan Sosial Ekonomi Pertanian Bogor Badan penelitian dan Pengembangan Pertanian. Departemen Pertanian Indonesia.

Rahadiani, Anak. 2014. Partisipasi Masyarakat Sekitar Danau Beratan dalam Konservasi Sumber Daya Air,

Setiawan, B. 2010. Menganalisa Statistik Bisnis dan Ekonomi dengan SPSS Versi 21. Peberbit Andi Yogyakarta

Sugiyono. 2007. Metode Penelitian Administrasi. Alfabeta. Bandung.

Sugiyono. 2010. Statistika untuk Penelitian. Alfabeta. Bandung.

Sumardjo, Gatot Irianto. 2007. Pedoman Teknis Pengembangan Pengelolaan Irigasi Partisifatif, Direktorat pengelolaan Air. Direktorat Jenderal Pengelolaan Lahan dan Air Departemen Pertanian.

Yuliani, T. 2003. Kajian Tingkat PartisipatifnDalam Operasi dan Pemeliharaan Untuk Perkumpulan Petani Pemakai Air (P3A) di Daerah Irigasi Boro Kabupaten Purworejo. Universitas Diponegoro

Pakpahan. D. Suripin dan Sachro,ss. 2014 Kajian Optimalisasi Sistem Irigasi 
Rawa (Studi Kasus Daerah Rawa Semangga Kabupaten Propinsi Papua). Jurnal Ilmu dan Terapan Teknik Sipil. 20(2). 155-166

Sittadewi, E.H. 2008. Kondisi Lahan Pasang Surut Kawasan Rawa Pening Dan Potensi Pemanfaatannya. Jurnal teknik Lingkungan. 9(3). 294-301 